\title{
Introduction: Matter and Perception - Interactions between Metaphysics, Epistemology, and Natural Philosophy
}

\author{
Doina-Cristina Rusu \\ Faculty of Philosophy, University of Groningen, Groningen, The Netherlands \\ d.rusu@rug.nl
}

While the concept of 'matter' has received much attention from scholars of early modern philosophy, this is not the case with 'perception,' and is even less so when it comes to a consideration of the relationship between the two. One reason might be the fact that by 'perception' we usually understand sense-perception, and we think of the empirical theory according to which we acquire knowledge about the world through our senses, when these capture the sensible qualities of external objects. But what about Leibniz's claim that monads, simple immaterial beings, have perception, and that sensation is a more complex type of perception? ${ }^{1}$ According to Leibniz, the sufficient reason of change and (mechanical) motion in the material world is to be found in the perception of monads:

Moreover, we must confess that the perception, and what depends on it, is inexplicable in terms of mechanical reasons, that is, through shape and motions. [...] Furthermore, this is all one can find in the simple substance - that is, perceptions and their changes. It is also in this alone that all the internal actions of simple substances can consist. ${ }^{2}$

For Leibniz, the mechanical interactions of material bodies will ultimately be accounted for in terms of the non-mechanical actions of simple substances, namely, the perception of monads. Perception and appetition - the monads' tendency to go from one perception to another - are their two characteristics and the principles of change. As principles of change, they are the causes of all

1 Gottfried Wilhelm Leibniz, The Principles of Philosophy, or, The Monadology, in Roger Ariew and Daniel Garber, ed. and trans., Philosophical Essays (Indianapolis, IN, 1989), 215. The same idea is explained in The Principle of Nature and Grace, Based on Reason, ibid., 208.

2 Leibniz, Monadology, 15; italics in the original. 
motion in the created world. This is to say that, at the basic level, the building blocks of the world, the monads, are purely perceptive beings, and perception cannot be accounted for in terms of something else, as it is foundational.

The context in which Leibniz talks about the perception of monads is a metaphysical one, while the aforementioned empirical discussion of acquiring knowledge about external objects though sense-perception pertains to an epistemological context. Of course, the two contexts are closely connected. According to Leibniz, sensation is a special kind of perception, specific only to animals and humans because, for these beings, perception can be accompanied by memory. Through perception, simple substances represent other simple substances; through sense-perception, composed substances represent other composed substances. ${ }^{3}$

Leibniz's metaphysical account of perception needs to be seen against a rich Renaissance background. One of the first authors to make perception foundational for bodies and natural phenomena was Bernardino Telesio, in his De rerum natura (first edition in two books, 1570; second edition in nine books, 1596). In Giglioni's paraphrase, Telesio defines perception or sentience as "the ability present in active principles (heat and cold) to recognise similarities and differences while they proceed to shape matter through movements of pursuit and avoidance." ${ }^{4}$ As for Leibniz, Telesio's account of perception is transformative, but contrary to Leibniz, Telesio's perception is corporeal, as it presupposes physical interaction. By positing sensation or perception at the basic level of material interactions, Telesio avoids the need for an immaterial entity, such as substantial forms of the scholastics, in order to explain activity in general and life in particular. To be perceptive means to be active, and thus, given that everything is perceptive of its surroundings, everything is alive, animated, vital. Of course, there is a difference between a stone, a plant, and an animal; but this difference is one of degree and not of kind.

3 For Leibniz there must be continuity between the level of monads and that of composite beings. In a letter to Lady Masham, he clearly expresses the connection between perception at the two levels: "[M]y entire Hypothesis comes down to recognizing in imperceptible and unobservable substances something proportional to what can be observed in those things within our reach. Hence, assuming for the moment that there is in us a simple Being endowed with Action and Perception, I find that Nature would be scarcely unified if the particle of matter making up human bodies were the only one endowed with features that make it infinitely different to the rest (even physically) and completely heterogeneous with respect to all other known bodies." (Gottfried Wilhelm Leibniz to Damaris Masham, May 1704, in Jacqueline Broad, ed., Women Philosophers of Seventeenth-Century England: Selected Correspondence $(\mathrm{New}$ York, 2020), 197).

4 Guido Giglioni, "The First of the Moderns or the Last of the Ancients? Bernardino Telesio on Nature and Sentience," Bruniana \& Campanelliana, 16 (2010), 69-87, 72. 
Several natural philosophers in the second half of the sixteenth and the seventeenth centuries followed Telesio's naturalist approach and used matter's perceptivity to explain a wide range of phenomena. One of the most prominent is no doubt Tommaso Campanella, Telesio's advocate. In his On the Sense of Things and on Magic (Del senso delle cose e della magia, 1604), Campanella makes perception the principle of identity: through perceiving the surrounding bodies, each body becomes aware of its own existence, at the same time as it recognises similitudes and differences in the other bodies. Every action is thus a reaction to the act of perception: bodies accept or reject other bodies depending on whether the latter help or hinder their self-preservation. ${ }^{5}$ Francis Bacon, Jan Baptista van Helmont, Francis Glisson, Anne Conway, and Margaret Cavendish, to name a few authors before Leibniz, make use of the concept of perception in a metaphysical context, and they all promote a vitalist matter theory, in some cases as a clear counterpart to the mechanical philosophy, which presents matter as dead and inert.

Two of the papers in this thematic issue deal with this metaphysical aspect. While Dana Jalobeanu shows how Bacon creates instruments able to measure the subtle perception of bodies, the ontological interpretation which Laura Georgescu offers of Cavendish's approach to perception seems to imply that the intimate knowledge of the other bodies' perceptive actions is not a matter of measurement, but of interacting with these actions and experiencing them.

Moreover, Georgescu's paper argues that for Cavendish, metaphysical perception cannot be understood in analogy with sense-perception, since they are completely different.

In this metaphysical context, matter perceives and is being perceived, which is to say that in perception, there is no active and passive body, as there is activity everywhere. This rejection of the active-passive distinction becomes more problematic in the epistemological context: Are the senses active or passive? Is the perceived object active or passive? These questions received different answers depending on the tradition to which the authors discussed in this thematic issue belonged. The answer depended on the status of the perceived entity, this is to say, on the underlying matter theory. ${ }^{6}$

5 See Guido Giglioni, "Senso, linguaggio e divinatione nella filosofia di Tommaso Campanella," Rivista di Storia della Filosofia, 64 (2009), 309-320.

6 For an overview of different answers to the issue of active sense perception, see Jose Felipe Silva and Mikko Yrjonsuuri, eds., Active Perception in the History of Philosophy. From Plato to Modern Philosophy (Cham, 2014). On sense perception, see Simo Knuuttila and Pekka Kärkkäinen, eds., Theories of Perception in Medieval and Early Modern Philosophy (Dordrecht, 2008). 
For Aristotelian-scholastic authors, bodies have primary qualities (heat, cold, moisture, and dryness), secondary qualities (depending on the combinations of the primary qualities) and tertiary or occult qualities (which depend on their form). Primary and secondary qualities depend on matter, but the act of perception does not always involve material entities. Many authors used explanations in term of immaterial species emitted by the objects and received by the senses. ${ }^{7}$ In the mechanical philosophy, which became prevalent in the seventeenth century, the distinction between primary and secondary qualities changed drastically. Secondary qualities now referred to the sensory qualities and were dependent on the perceiver. At the same time, they remain reducible to the primary qualities, the size, shape, motion, solidity, and texture of the particles of matter. The act of sense-perception itself will be nothing more than matter in motion.

This special issue discusses both Aristotelian non-reductive approaches as well as the mechanical reductive ones. Lucie Čermáková-Strnadovás paper deals with the use of the sensory qualities in classifying plants, their relations to the four elements and the four primary qualities, and the relevance of 'affinities' in establishing connections between plants. At the other end of the spectrum, we find Robert Hooke who, according to Ian Lawson's essay, thought that the microscope, even if it cannot capture the ultimate particles of matter, can at least rule out all non-mechanical explanations. Lawson shows that, for Hooke, the arrangements of matter are enough to account for all the actions of bodies. We can thus notice a shift in the importance of senses: for the Aristotelians, taste is the sense that can capture the nature of a plant, because of its connection with medicinal properties; for corpuscularians, sight is more relevant because everything can be reduced to the size, shape, and arrangement of particles. The changes from a non-reductive to a reductive framework are captured by Albrecht Heeffer's essay, which looks at how new instrumentation turned what were primary qualities for the Aristoteliansinto a corpuscularian phenomenon.

Even if secondary sensory qualities are just 'phantasms' and do not exist except in our minds, they are the only access we have to the external world. It is here that natural philosophy is needed. And its purpose is twofold: on the one hand, natural philosophy aims at perfecting our senses so that the sensation is as accurate as possible; and on the other, it aims at establishing rules for the reduction of secondary to primary qualities. In the course of the seventeenth

7 For discussion on species and sense-perception, see Leen Spruit, "Sensation and Perception," in Dana Jalobeanu and Charles Wolfe, eds., Encyclopedia of Early Modern Philosophy and the Sciences (Cham, 2020), doi:10.1007/978-3-319-20791-9_397-1. 
century, instruments started to play an important role for both purposes, and several papers contained in this special issue provide an overview of how instruments became more important as mediators between senses and objects. Čermáková-Strnadovás paper shows that there is no need for instruments, since the classification of plants can be done using our senses. Further papers show how, within the context of the experimental philosophy, instruments became indispensable. Heeffer's article investigates the ways in which heat and cold lost their status as primary elementary qualities, and how these same phenomena, the understandings of which eventually coalesced into a single phenomenon known as 'temperature,' were studied, measured and quantified through a variety of instruments. Further, while conceiving instruments as necessary to the study of nature - owing to the limitation of the human senses - Bacon and Hooke, nevertheless represent two different concepts of what can be perceived. On the one hand, Jalobeanu argues that Bacon's instruments can measure the subtlety of nature precisely because matter is perceptive at its basic level; the human senses are too dull to capture this subtlety, and this is why the natural philosopher must make use of instruments. On the other hand, Lawson argues that for Hooke, instruments can reveal that there is nothing more to bodies than matter arranged in a certain way.

Each of the following five contributions thus offers a different image of the relationship between matter and perception in early modern philosophy, either in the field of epistemology, metaphysics, natural philosophy, or at their intersections.

In the first paper, "The Role of Sensory Qualities in Renaissance Natural History: The Case of Mattioli's Herbal," Lucie Čermáková-Strnadová analyses the richness of the sensory approach to plants in the context of making herbaria in the sixteenth century. Taking the texts of Pietro Andrea Mattioli (1501-1577) as an example, this paper analyses how the author identified the plants described by Dioscorides through a comparison of tastes, smells, shapes and colours. The use of sensory qualities in the identification and classification of plants was far from random. Čermáková-Strnadová shows how each sense has its own role in the process: taste was relevant for establishing the nature of a plant, since this quality revealed the medicinal properties; and visual qualities were used to distinguish between varieties of plants.

In his paper "Quantifications of the Secondary Qualities, Heat and Cold, on the Earliest Scales of Thermoscopes," Albrecht Heeffer focuses on a diversity of scales used between 1610 and 1640 to measure temperature, each pertaining to a different philosophical tradition, and each conceptualising the qualities of heat and cold in a different way. The initial nominal scale, with four gradations corresponding to the four elements, temperaments and degrees of humour, 
was developed into ordinal, linear, and numerical scales. In parallel with this process, secondary qualities of heat and cold became objectified and quantifiable as an observable phenomenon.

In her paper "Francis Bacon's 'Perceptive' Instruments," Dana Jalobeanu aims to bridge the gap between Bacon's qualitative view of nature and his attempts at measuring natural phenomena. Focusing on two key-concepts, those of the 'orbs of virtue' and of 'perception,' Jalobeanu analyses the use of instruments designed to measure properties and virtues, where human senses are too dull to notice subtle differences and changes. These initially metaphysical concepts, once used by Bacon in an experimental setting, acquire new meanings and can be used to guide more sophisticated experimental investigations.

Laura Georgescu offers a new interpretation of Cavendish's concept of 'perceptive knowledge' in her essay 'Self-knowledge, Perception, and Margaret Cavendish's Metaphysics of the Individual". Placing perception in a metaphysical rather than an epistemological framework, this article contrasts self-knowledge and perceptive knowledge as characteristics of parts of matter. Self-knowledge makes of each part of matter a unique individual, but it is the purely relational quality of perception that draws together the parts into the whole of nature and accounts for their interconnectedness.

Ian Lawson's paper, "What Did Hooke Want from the Microscope? Magnification, Matter Theory and Mechanism," illustrates how, from the early Micrographia through to his later lectures, Robert Hooke changed his mind regarding the power of the microscope. If initially he was confident that the microscope could be improved to such a point that it would show the inner structure of matter and its motions, Hooke later came to believe that the ultimate causes of certain phenomena could not be captured by lenses, not even under ideal magnification, and not because these causes were occult or overly subtle, but because they did not exist. All that the world constituted for Hooke was arrangements of matter at a multitude of layers. 